\title{
Clobetasol Propionate
}

National Cancer Institute

\section{Source}

National Cancer Institute. Clobetasol Propionate. NCI Thesaurus. Code C28934.

The propionate salt form of clobetasol, a topical synthetic corticosteroid with antiinflammatory, anti-pruritic, and vasoconstrictive properties. Clobetasol propionate exerts its effect by binding to cytoplasmic glucocorticoid receptors and subsequently activates glucocorticoid receptor mediated gene expression. This results in synthesis of certain anti-inflammatory proteins, while inhibiting the synthesis of certain inflammatory mediators. Specifically, clobetasol propionate appears to induce phospholipase A2 inhibitory proteins, thereby controlling the release of the inflammatory precursor arachidonic acid from membrane phospholipids by phospholipase A2. 